\title{
Study on the Linear Vanishing Section Ratio of Earthen Sites and Anthropogenic Influence from the Perspective of Population Density
}

Yumin Du ( $\nabla$ duym@nwpu.edu.cn )

Northwestern Polytechnical University https://orcid.org/0000-0002-4871-9589

\section{Wenwu Chen}

Lanzhou University

Kai Cui

Lanzhou University of Technology

Wenqiang Dong

Northwestern Polytechnical University

Shuai Zhang

Lanzhou University

Qiyong Zhang

Lanzhou University

Research article

Keywords: Earthen sites, Linear vanishing section ratio, Ming Great Wall, Population density, Anthropogenic influence

Posted Date: May 17th, 2021

DOl: https://doi.org/10.21203/rs.3.rs-524855/v1

License: (c) (i) This work is licensed under a Creative Commons Attribution 4.0 International License.

Read Full License 


\section{Study on the Linear Vanishing Section Ratio of Earthen Sites and Anthropogenic Influence from the Perspective of Population Density}

Yumin $\mathrm{Du}^{1,2 *}$, Wenwu Chen ${ }^{3}$, Kai $\mathrm{Cui}^{4}$, Wenqiang Dong ${ }^{1,2}$, Shuai Zhang ${ }^{3}$ and Qiyong Zhang ${ }^{3}$

${ }^{1}$ Institute of Culture and Heritage, Northwestern Polytechnical University, Xi’an 710072, China;

${ }^{2}$ Key Scientific Research Base of the State Administration of Cultural Heritage for the Conservation and Restoration of Murals and Material Science Research, Northwestern Polytechnical University, Xi'an 710072, China;

${ }^{3}$ Key Laboratory of Mechanics on Disaster and Environment in Western China, College of Civil Engineering and Mechanics, Lanzhou University, Lanzhou 730000, China;

${ }^{4}$ Western Center for Disaster Mitigation in Civil Engineering of Ministry of Education of China, School of Civil Engineering, Lanzhou University of Technology, Lanzhou 730050, China

*Corresponding author: Yumin Du

Institute of Culture and Heritage, Northwestern Polytechnical University, Xi'an 710072, China;

Email: duym@nwpu.edu.cn

Telephone number: +8602988460550

Fax number: +8602988460550

ORCID: 0000-0002-4871-9589

\section{Acknowledgments}

This work was supported by the funding from National Key R\&D Plan Program of China [Grant No. 2020YFC1522201 and No. 2020YFC1521904], the cultural relics protection technology project of State Administration of Cultural Heritage of the People's Republic of China [Grant No. 2013-YB-SQ-120] and the National Natural Science Foundation of China [Grant No. 41562015 and No. 52068050]. 


\title{
Study on the Linear Vanishing Section Ratio of Earthen Sites and Anthropogenic Influence from the Perspective of Population Density
}

\begin{abstract}
Having extremely high artistic, scientific and social values, earthen sites are widely distributed in China, which are important cultural relic resources of mankind. Due to accumulated natural erosions and human activities, however, earthen sites have been greatly damaged and have even vanished many sections, so that they are seriously threatened by extinction. In the circumstances, acquiring the conservation status of earthen sites is a vital prerequisite for the subsequent targeted protection. In this paper, as a world-renowned heritage site, the castles of the Ming Great Wall located in Qinghai Province were selected as the research object. A novel indicator namely the linear vanishing section ratio (L-VSR) was proposed and its value was classified as five levels to quantitatively characterize the specific conservation status of such sites. Based on the assessment results, the castles at the excellent status constituted the minimum proportion, while the castles at the very poor status represented the largest percentage, reflecting the grave situation of earthen sites. Furthermore, applying population distribution models into the linear fitting combined with the population density (PD), the positive correlation between PD and L-VSR was obtained to reveal the anthropogenic influence on the destruction of earthen sites. This study provides a new thought to quantitatively characterize the preservation conditions of earthen sites and also indicates the effect of human activities on the damage of earthen sites from the population perspective. Hence, it is beneficial to the overall damage assessment of earthen sites, and also meaningful to their further preservation and protective planning.
\end{abstract}

Keywords: Earthen sites; Linear vanishing section ratio; Ming Great Wall; Population density; Anthropogenic influence

\section{Introduction}

Earthen sites are a kind of typical architectural sites mainly built with soil materials, which are widely distributed in the whole world, such as Ajina Tepa, Tajikistan [1], Alhambra, Spain [2], Casa Grande Ruins National Monument, the United States [3], Çatalhöyük, Turkey [4], Great Wall [5] and Tulou, China [6]. Having extremely high artistic, scientific and social values, earthen sites in China have a long historical process stretched from the Palaeolithic Age to modern times, reflecting the evolution of Chinese civilization and the improvement of social productivity [7,8]. Undoubtedly, they are important cultural relic resources of mankind. Exposed to long-term natural forces including wind and rain erosions and human activities, however, earthen sites have developed many deteriorations such as sapping, cracks, scaling off, gullies, collapses, etc., severely threatening their safe occurrence [5,9-12]. Under the circumstances, most earthen sites have been seriously damaged and even have vanished many sections due to the development of deteriorations and natural/human influences in the past thousands of years, so that they are greatly threatened by extinction. Consequently, taking targeted protection for earthen sites is very urgent, and acquiring the conservation status of earthen sites starting from these vanishing sections is a vital prerequisite for the protection work.

So far, many scholars mainly focused on the mechanisms of deterioration development of earthen sites. Four deterioration categories including property deterioration, structure damaging, structure collapse, and site destroying were summarized [10]. On the basis of field investigation and laboratory analysis, four main deterioration modes, namely wind-related deterioration, water-related deterioration, temperature-related deterioration and chemical-related deterioration in Jiaohe ruins in China were identified [12]. A model characterizing the deterioration at earthen sites of the Ming Great Wall in Qinghai Province was also proposed to reveal the mechanisms and evolution of deterioration from a macro perspective [5]. Based on these deteriorations development, the damage assessment of earthen sites was studied by means of multicriteria decision-making (MDCM) and machine learning methods combined with environmental factors and building materials indices, which has revealed earthen sites' local damages caused by the development of deteriorations [9,13]. However, a scientific approach to assess the overall damage of earthen sites was still lacked to quantitatively illustrate these sites' conservation status. The effects of natural factors on earthen sites such as wind, rain, earthquake, etc., have mostly been studied [11,14,15], but few researches focused on their quantitative influence of human activities. 
In this paper, the authors selected 46 castles of the Ming Great Wall located in Qinghai Province, China as the research object, and proposed a novel indicator, namely the linear vanishing section ratio (L-VSR) to characterize such sites' conservation. Moreover, the anthropogenic influence on the L-VSR was researched from the perspective of population density (PD). By applying population distribution models, PD was further correlated with L-VSR to show the effect of human activities on the damage of earthen sites from the macroscopic perspective. As seen from the research results, it is potential to promote the indicator and model proposed in this study into earthen sites and other architectural types of the Ming Great Wall. The research findings have beneficial references to the overall damage assessment of earthen sites, and also meaningful to their further preservation and protective planning.

\section{Study Objects}

The Great Wall built in the Ming Dynasty, called the Ming Great Wall, was the most renowned military defensive project in ancient China, which has been designated as a World Heritage in 1987 [16]. The Ming Great Wall is a complex military network consists of walls, trenches, beacon towers, passes, castles, precipitous mountain areas, marine insurance, etc., and these building types played their respective roles and cooperated with each other in the military defense phase [17]. In the whole Great Wall system, the castle is a core element with multiple functions such as the exchange of military information, goods and people, and the management of important civil affairs [18,19].

Located independently from the Great Wall mainline in "nine towns", the Ming Great Wall in Qinghai Province is a significant section of the whole Great Wall, which was built from 1546 to 1596, surrounding Xining Wei with an arch shape $[17,20]$. As the rammed earth is the dominant building material vulnerable to climate, the Ming Great Wall in Qinghai Province has currently existed as a form of earthen sites exposed under environmental impacts for about 500 years [13,21]. Being a significant part of the Ming Great Wall, there are 46 castles located in Qinghai Province (Fig. 1), which were selected as the study object to research their conservation status. The information on these sites has been listed in Table 1. By collecting archaeological materials of such sites, the linear circumference and remaining length of walls can be acquired. Then L-VSR can be calculated to indicate the conservation status of castles.

\section{Table 1}

The information of castles of the Ming Great Wall in Qinghai Province

\begin{tabular}{|c|c|c|c|}
\hline Number & Name & Number & Name \\
\hline 1 & No.1 of Chengbeihou Castle & 24 & Weiyuan Castle \\
\hline 2 & No.2 of Chengbeihou Castle & 25 & Miaogou Castle \\
\hline 3 & Najiazhuang Castle & 26 & Xin Castle \\
\hline 4 & Mengjiawan Castle & 28 & Pingle Castle \\
\hline 5 & Nianmugou Castle & 29 & Gu Castle \\
\hline 6 & Nianxiangou Castle & 30 & Yangpotai Castle \\
\hline 7 & Naozhuang Castle & 31 & Boshiying Castle \\
\hline 8 & No.1 of Simozhuang Castle & 32 & Laoyou Castle \\
\hline 9 & No.2 of Simozhuang Castle & 33 & Jiaerzang Castle \\
\hline 10 & Shangyamen Castle & 34 & Xincheng Castle \\
\hline 11 & Lianxing Castle & 35 & Yuanshaner Castle \\
\hline 12 & Qijia Castle & 36 & Dongjiawan Castle \\
\hline 13 & Dieergou Castle & 37 & Xujiazhai Castle \\
\hline 14 & Laoya Ancient Castle & 38 & Tonghai Castle \\
\hline 15 & Nianbo Ancient Castle & Songshu Castle \\
\hline 16 & Yuanjiazhuang Castle & & \\
\hline 17 & Maying Castle & & 27 \\
\hline
\end{tabular}




\begin{tabular}{|c|c|c|c|}
\hline 18 & Beizhuang Ancient Castle & 41 & Gushan Ancient Castle \\
\hline 19 & Shijia Castle & 42 & Baishen Castle \\
\hline 20 & Xintian Castle & 43 & Zhongcun Castle \\
\hline 21 & Baiya Castle & 44 & Zongzhai Castle \\
\hline 22 & Datongyuan Castle & 45 & Xining Wei \\
\hline 23 & Chenjiatai Castle & 46 & Guide Ancient Castle \\
\hline
\end{tabular}

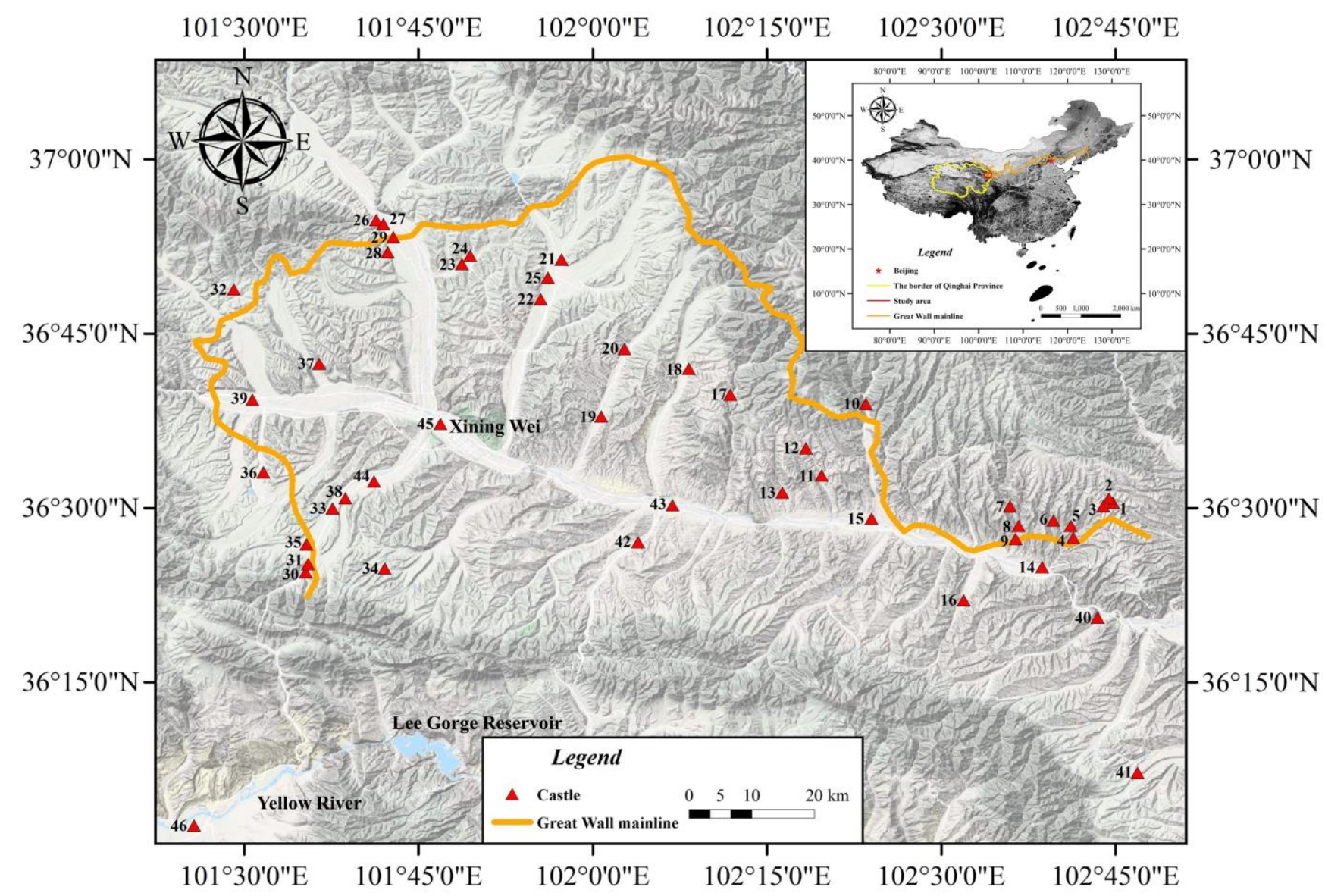

Fig. 1. The distribution of castles of the Ming Great Wall in Qinghai Province.

\section{Methods}

In this research, the authors mainly referred to archaeological materials from the Qinghai provincial administration of cultural relics and the Qinghai Bureau of surveying and mapping to collect the plane graph of castles. Then the data castles' circumference length (CL) and remaining length (RL) can be acquired from the measurement of plane graphs in Auto CAD. The authors proposed a novel indicator called the linear vanishing section ratio (L-VSR) which indicates how many sections of earthen sites in these castles have been vanished by the following calculation:

$$
\mathrm{L}-\mathrm{VSR}=1-(\mathrm{RL} / \mathrm{CL})
$$

where RL/CL is the remaining length ratio (RLR) shown in Eq. (2):

$$
\mathrm{RLR}=\mathrm{RL} / \mathrm{CL}
$$

The value of L-VSR can be classified as 5 levels to quantitatively characterize the specific conservation status of castles, including excellent $(\mathrm{E})(0-10 \%)$, good $(\mathrm{G})(10 \%-25 \%)$, fair $(\mathrm{F})(25 \%-50 \%)$, poor $(\mathrm{P})(50 \%-75 \%)$, and very poor (VP) $(75 \%$ $100 \%$ ). Because there has not been a uniform method of damage division for earthen sites so far, in this research the authors mainly referred to the classification approach used for the rock quality designation (RQD) to provide a quantitative estimate of rock mass quality from drill core logs [22]. 
After that, the authors introduced the index of population density (PD) into this research. The PD indicates the number of people living in each unit of area (such as a square kilometer), which is an important indicator to measure the distribution of population in a region [23]. Its formula was shown in Eq. (3):

\section{$\mathrm{PD}=\mathrm{PN} / \mathrm{RA}$}

where $\mathrm{PN}$ is the number of population in a certain region, and RA is the area of that region.

Finally, four frequently-used single core population distribution models were applied to achieve positive correlations between PD and L-VSR, showing the influence of human activities on the conservation of earthen sites from a macroscopic perspective.

\section{Results and Discussion}

\subsection{Linear Vanishing Section Ratio (L-VSR)}

The authors firstly calculated the L-VSR value of the No.1 of Chengbeihou Castle by measuring its size on the plane graph in Auto CAD. As shown in Fig. 2, with the side length of $123 \mathrm{~m}$ and $86 \mathrm{~m}$, its CL and RL are $418 \mathrm{~m}$ and $149.4 \mathrm{~m}$ (the length of the east wall, south wall, west wall and north wall are $2.5 \mathrm{~m}, 62.1 \mathrm{~m}, 38.1 \mathrm{~m}$, and $46.7 \mathrm{~m}$ respectively). After that, on the basis of Eq. (2) and Eq. (1), its RLR and L-VSR are $35.74 \%$ and $64.26 \%$.
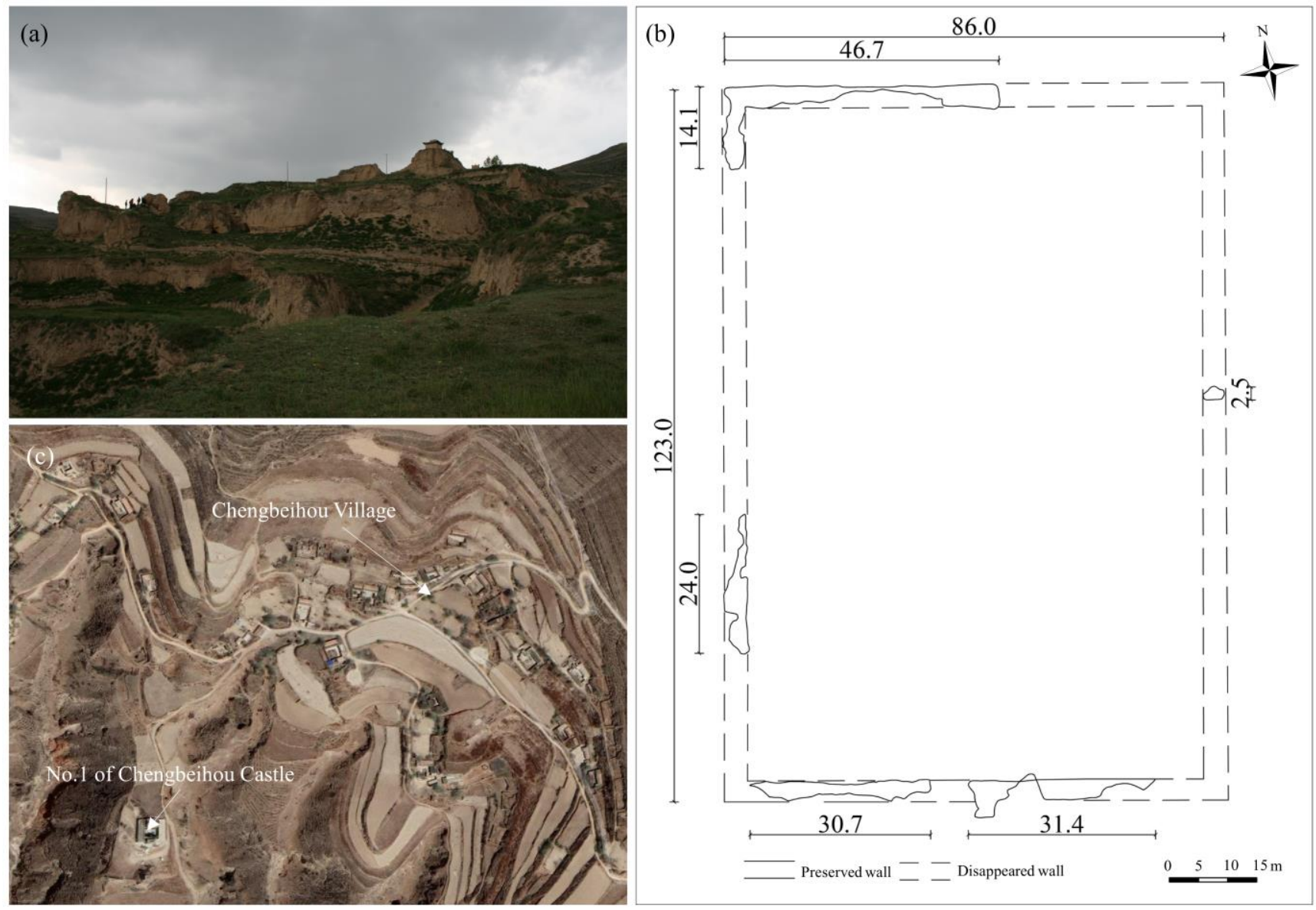

Fig. 2. No.1 of Chengbeihou Castle: a front view, b plane graph, and c satellite image (from Google map).

Using the same procedures and methods, all 46 castles' L-VSR values were acquired. The data of RL and CL were collected and then L-VSR data were calculated based on Eq. (1), and the conservation status was also given according to the L-VSR values and classification levels, which were listed in Table 2.

\section{Table 2}

The length data and L-VSR of castles of the Ming Great Wall in Qinghai Province 


\begin{tabular}{|c|c|c|c|c|c|}
\hline Number & $\begin{array}{l}\text { Circumference Length } \\
\text { (CL) }\end{array}$ & $\begin{array}{l}\text { Remaining Length } \\
\text { (RL) }\end{array}$ & $\begin{array}{c}\text { Remaining Length } \\
\text { Ratio } \\
\text { (RLR) }\end{array}$ & $\begin{array}{c}\text { Linear Vanishing } \\
\text { Section Ratio } \\
\text { (L-VSR) }\end{array}$ & $\begin{array}{c}\text { Conservation } \\
\text { Status }\end{array}$ \\
\hline 1 & 418.00 & 149.40 & $35.74 \%$ & $64.26 \%$ & $\mathrm{P}$ \\
\hline 2 & 68.00 & 32.50 & $47.79 \%$ & $52.21 \%$ & $\mathrm{P}$ \\
\hline 3 & 400.00 & 305.80 & $76.45 \%$ & $23.55 \%$ & G \\
\hline 4 & 82.20 & 20.40 & $24.82 \%$ & $75.18 \%$ & $\mathrm{VP}$ \\
\hline 5 & 59.20 & 0.00 & $0.00 \%$ & $100.00 \%$ & $\mathrm{VP}$ \\
\hline 6 & 294.00 & 235.00 & $79.93 \%$ & $20.07 \%$ & $\mathrm{G}$ \\
\hline 7 & 188.00 & 86.35 & $45.93 \%$ & $54.07 \%$ & $\mathrm{P}$ \\
\hline 8 & 134.00 & 18.00 & $13.43 \%$ & $86.57 \%$ & $\mathrm{VP}$ \\
\hline 9 & 108.00 & 69.90 & $64.72 \%$ & $35.28 \%$ & $\mathrm{~F}$ \\
\hline 10 & 180.00 & 22.30 & $12.39 \%$ & $87.61 \%$ & $\mathrm{VP}$ \\
\hline 11 & 182.00 & 48.40 & $26.59 \%$ & $73.41 \%$ & $\mathrm{P}$ \\
\hline 12 & 220.00 & 7.50 & $3.41 \%$ & $96.59 \%$ & $\mathrm{VP}$ \\
\hline 13 & 240.00 & 34.90 & $14.54 \%$ & $85.46 \%$ & $\mathrm{VP}$ \\
\hline 14 & 315.00 & 9.93 & $3.15 \%$ & $96.85 \%$ & $\mathrm{VP}$ \\
\hline 15 & 1572.00 & 465.25 & $29.60 \%$ & $70.40 \%$ & $\mathrm{P}$ \\
\hline 16 & 542.00 & 114.00 & $21.03 \%$ & $78.97 \%$ & $\mathrm{VP}$ \\
\hline 17 & 287.20 & 241.60 & $84.12 \%$ & $15.88 \%$ & G \\
\hline 18 & 267.00 & 235.10 & $88.05 \%$ & $11.95 \%$ & G \\
\hline 19 & 340.00 & 245.50 & $72.21 \%$ & $27.79 \%$ & $\mathrm{~F}$ \\
\hline 20 & 658.00 & 361.50 & $54.94 \%$ & $45.06 \%$ & $\mathrm{~F}$ \\
\hline 21 & 297.00 & 247.10 & $83.20 \%$ & $16.80 \%$ & G \\
\hline 22 & 243.00 & 185.40 & $76.30 \%$ & $23.70 \%$ & G \\
\hline 23 & 245.00 & 81.80 & $33.39 \%$ & $66.61 \%$ & $\mathrm{P}$ \\
\hline 24 & 465.00 & 380.70 & $81.87 \%$ & $18.13 \%$ & G \\
\hline 25 & 799.00 & 396.50 & $49.62 \%$ & $50.38 \%$ & $\mathrm{P}$ \\
\hline 26 & 228.00 & 77.50 & $33.99 \%$ & $66.01 \%$ & $\mathrm{P}$ \\
\hline 27 & 724.00 & 157.80 & $21.80 \%$ & $78.20 \%$ & $\mathrm{VP}$ \\
\hline 28 & 166.00 & 102.30 & $61.63 \%$ & $38.37 \%$ & $\mathrm{~F}$ \\
\hline 29 & 952.00 & 151.80 & $15.95 \%$ & $84.05 \%$ & VP \\
\hline 30 & 80.00 & 3.10 & $3.88 \%$ & $96.13 \%$ & VP \\
\hline 31 & 66.00 & 8.00 & $12.12 \%$ & $87.88 \%$ & $\mathrm{VP}$ \\
\hline 32 & 104.00 & 89.30 & $85.87 \%$ & $14.13 \%$ & $\mathrm{G}$ \\
\hline 33 & 446.00 & 229.00 & $51.35 \%$ & $48.65 \%$ & $\mathrm{~F}$ \\
\hline 34 & 355.00 & 250.40 & $70.54 \%$ & $29.46 \%$ & $\mathrm{~F}$ \\
\hline 35 & 752.00 & 659.20 & $87.66 \%$ & $12.34 \%$ & $\mathrm{G}$ \\
\hline 36 & 148.00 & 109.20 & $73.78 \%$ & $26.22 \%$ & $\mathrm{~F}$ \\
\hline 37 & 324.00 & 232.60 & $71.79 \%$ & $28.21 \%$ & $\mathrm{~F}$ \\
\hline 38 & 1320.00 & 126.70 & $9.60 \%$ & $90.40 \%$ & VP \\
\hline 39 & 1100.00 & 7.00 & $0.64 \%$ & $99.36 \%$ & $\mathrm{VP}$ \\
\hline 40 & 1093.00 & 470.67 & $43.06 \%$ & $56.94 \%$ & $\mathrm{P}$ \\
\hline 41 & 1006.00 & 572.50 & $56.91 \%$ & $43.09 \%$ & $\mathrm{~F}$ \\
\hline
\end{tabular}




\begin{tabular}{|c|c|c|c|c|c|}
\hline 42 & 744.00 & 280.00 & $37.63 \%$ & $62.37 \%$ & $\mathrm{P}$ \\
\hline 43 & $/$ & 22.00 & $/$ & $/$ & $/$ \\
\hline 44 & 744.00 & 53.30 & $7.16 \%$ & $92.84 \%$ & $\mathrm{VP}$ \\
\hline 45 & 4500.00 & 296.70 & $6.59 \%$ & $93.41 \%$ & $\mathrm{VP}$ \\
\hline 46 & 2040.00 & 1531.60 & $75.08 \%$ & $24.92 \%$ & $\mathrm{G}$ \\
\hline
\end{tabular}

Note: the circumference length data of No. 43 castle cannot be obtained because it has been damaged very severely and from historical documents, there were no related records about its size.

From Table 2, castles' conservation status can be acquired based on their L-VSR values and corresponding classification ranges: there are no castles at the $\mathrm{E}$ status, 10 castles at the $\mathrm{G}$ status making up 22\% of the total castles, 9 castles at the $\mathrm{F}$ status accounting for 20\%, 10 castles (22\%) at the P status, and 16 castles (36\%) at the VP status, respectively (Fig. 3). Hence, the castles at the excellent status constituted the minimum proportion, while the castles at the very poor status represented the largest percentage. There are more than half of the castles in the poor condition or even worse. These grading evaluation results have reflected the grave situation of earthen sites.

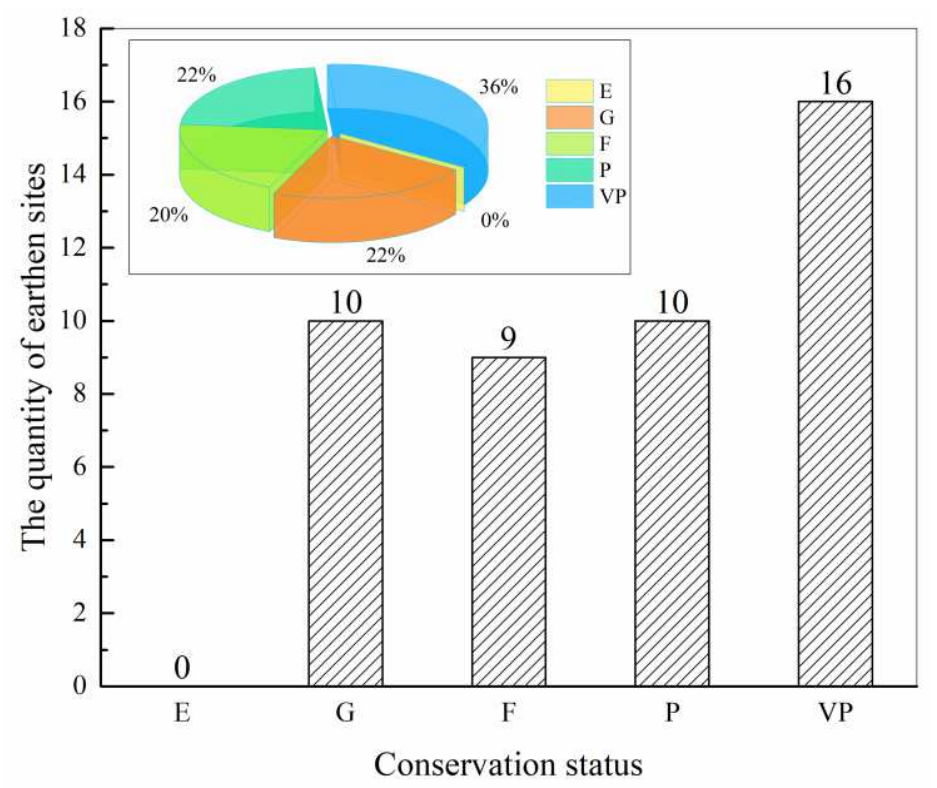

Fig. 3. The conservation status of castles in Qinghai Province

\subsection{Population Density (PD)}

In this study, most castles are located in or nearby a certain village. The authors collected the number of residential populations in these villages from archaeological materials provided by the Qinghai Bureau of Cultural Heritage, and measured the living area of such villages via the software of Rivermap X3. Then the villages' PD can be further calculated. The related data were listed in Table 3.

Combined with castles' conservation status results acquired before, the authors averaged all PD data of villages where the castles in each same damage level are located. As shown in Fig. 4, with the increment of overall damage level, the average PD data steadily increased from 4860 number per $\mathrm{km}^{2}$ in the $\mathrm{G}$ status to 8679 number per $\mathrm{km}^{2}$ in the VP status. This means that the conservation status of earthen sites would worsen as the surrounding population grows. Thus, the influence of human activities on the conservation of earthen sites can be proved from the PD perspective.

\section{Table 3}

The population density of villages where the castles of the Ming Great Wall in Qinghai Province are located or nearby 


\begin{tabular}{|c|c|c|c|c|}
\hline $\begin{array}{l}\text { The number } \\
\text { of castles }\end{array}$ & The name of the village & $\begin{array}{l}\text { The number of } \\
\text { population (PN) }\end{array}$ & $\begin{array}{c}\text { The living area of the } \\
\text { village (RA) } / \mathrm{km}^{2}\end{array}$ & $\begin{array}{c}\text { Population density } \\
(\mathrm{PD}) / \text { number per } \mathrm{km}^{2}\end{array}$ \\
\hline 1 & Chengbeihou Village & 350 & 0.0532 & 6575 \\
\hline 2 & Chengbeihou Village & 350 & 0.0532 & 6575 \\
\hline 3 & Najiazhuang Village & 40 & 0.0044 & 8999 \\
\hline 4 & Mengjia Bay Village & 500 & 0.0701 & 7129 \\
\hline 5 & 1 & 1 & 1 & 1 \\
\hline 6 & Nianxiangou Village & 80 & 0.0309 & 2588 \\
\hline 7 & Naozhuang Village & 800 & 0.3494 & 2290 \\
\hline 8 & Simozhuang Village & 700 & 0.0363 & 19295 \\
\hline 9 & Simozhuang Village & 700 & 0.0363 & 19295 \\
\hline 10 & Shangyamen Village & 1000 & 0.2127 & 4702 \\
\hline 11 & Lianxing Village & 300 & 0.0507 & 5918 \\
\hline 12 & Qijiabao Village & 1000 & 0.1146 & 8727 \\
\hline 13 & DieergouVillage & 400 & 0.0518 & 7716 \\
\hline 14 & Laoya Village & 2000 & 0.1590 & 12579 \\
\hline 15 & Dengjia Village & 2000 & 0.1644 & 12168 \\
\hline 16 & Yuanjiazhuang Village & 900 & 0.0799 & 11271 \\
\hline 17 & Maying Village & 200 & 0.0240 & 8331 \\
\hline 18 & Beizhuang Village & 600 & 0.1272 & 4716 \\
\hline 19 & Shijia Village & 1000 & 0.1255 & 7966 \\
\hline 20 & Xintianbao Village & 700 & 0.2015 & 3474 \\
\hline 21 & Baiya Village & 700 & 0.2609 & 2683 \\
\hline 22 & Datongyuan Village & 2000 & 0.3099 & 6454 \\
\hline 23 & Chenjiatai Village & 700 & 0.1236 & 5664 \\
\hline 24 & Xiamaquan No.2 Village & 1000 & 0.2619 & 3819 \\
\hline 25 & Gucheng Village & 1000 & 0.0580 & 17250 \\
\hline 26 & Xiamiaogou Village & 500 & 0.1102 & 4538 \\
\hline 27 & Xincheng Village & 1386 & 0.1966 & 7049 \\
\hline 28 & Pingle Village & 500 & 0.3005 & 1664 \\
\hline 29 & Gucheng Village & 500 & 0.3180 & 1573 \\
\hline 30 & Yangpotai Village & 795 & 0.0655 & 12147 \\
\hline 31 & Shangxinzhuang Village & 2534 & 0.6115 & 4144 \\
\hline 32 & Boshiying Village & 1126 & 0.2607 & 4319 \\
\hline 33 & Eastern Village of Lushaer Town & 2116 & 0.2989 & 7079 \\
\hline 34 & Jiaerzang Village & 2070 & 0.7228 & 2864 \\
\hline 35 & Xincheng Village & 1206 & 0.2734 & 4412 \\
\hline 36 & Yuanershan Village & 2136 & 0.4322 & 4942 \\
\hline 37 & Dongjia Bay Village & 1581 & 0.4102 & 3854 \\
\hline 38 & Xujiazhai Village & 2109 & 0.4396 & 4798 \\
\hline 39 & Tonghai downtown Village & 1903 & 0.5467 & 3481 \\
\hline 40 & Songshu Village & 500 & 0.1311 & 3815 \\
\hline 41 & Gushan Village & 2000 & 0.7129 & 2805 \\
\hline 42 & Baijia Village & 1863 & 0.1191 & 15641 \\
\hline
\end{tabular}




\begin{tabular}{|c|c|c|c|c|}
\hline 43 & Pingan Village in town & 1300 & 0.2099 & 6194 \\
\hline 44 & Zongnan Village & 2000 & 0.3065 & 6525 \\
\hline 45 & Urban district of Xining City & 200000 & 10.5000 & 19048 \\
\hline 46 & Heyin Town & 22843 & 10.0100 & 2282 \\
\hline
\end{tabular}

Note: There is no village close to the No. 5 castle so its related village population was not considered in this research.

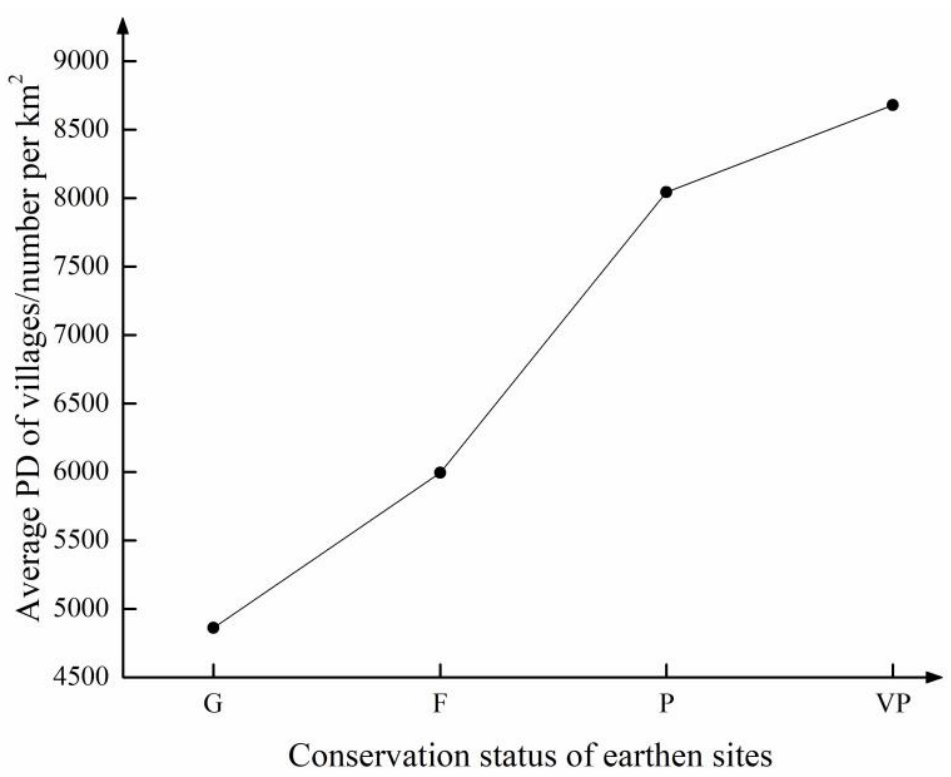

Fig. 4. The tendency graph between PD and conservation status of castles in Qinghai Province

\subsection{The correlation between PD and L-VSR}

After acquiring the data of PD of villages and L-VSR of castles of the Ming Great Wall in Qinghai Province, the correlation between PD and L-VSR was studied in order to further reveal the anthropogenic influence on the conservation of earthen sites. In fact, many castles in this research are not located in villages but nearby those villages, so the population density attenuation along with the distance between castles and villages should be considered. The four frequently-used single core population distribution models were applied, including the models of Clark, Smeed, Newling, and Cubic [24-27], to calculate the population density of castles with the attenuation of the PD of villages which have a certain distance from castles.

The Clark model used a negative exponential function to indicate the relationship between PD and distance from the residence center, shown in Eq. (4):

$$
\mathrm{PD}_{\mathrm{r}}=\mathrm{PD}_{0} \mathrm{e}^{-\mathrm{br}}
$$

The Smeed model's formula is a power exponential function shown in Eq. (5):

$$
\mathrm{PD}_{\mathrm{r}}=\mathrm{PD}_{0} \mathrm{r}^{\mathrm{b}}
$$

The Newling model is a quadratic exponential model shown in Eq. (6):

$$
\mathrm{PD}_{\mathrm{r}}=\mathrm{PD}_{0} \mathrm{e}^{\mathrm{br}+\mathrm{cr}^{2}}
$$

The Cubic model is a cubic function from Eq. (7):

$$
\mathrm{PD}_{\mathrm{r}}=\mathrm{PD}_{0} \mathrm{e}^{\mathrm{br}+\mathrm{cr}^{2}+\mathrm{dr}^{3}}
$$

where $\mathrm{PD}_{\mathrm{r}}$ is the population density of a place with the distance of $\mathrm{r}$ from the residence center, $\mathrm{PD}_{0}$ is the population density of the residence center, and b, c and d are parameters. In this study, the authors simplified the village as a point and if a castle is located in the village, their distance can be regarded as $0 \mathrm{~m}$. Furthermore, the $\mathrm{PD}_{\mathrm{r}}$ is the assumed population density of castles with the attenuation of the $\mathrm{PD}$ of villages, $\mathrm{PD}_{0}$ is the population density of villages, and $\mathrm{r}$ is the distance between the castle and village.

Combined with related archaeological materials and the software of Rivermap X3, we collected and measured the data of 
distances between castles and villages in which they are located or nearby, listed in Table 4. After that, it is assumed that there is a linear positive correlation between $\mathrm{PD}_{\mathrm{r}}$ and L-VSR. During processing related data, the $\mathrm{PD}_{0}$ and L-VSR of castles which have the same distance from villages where they are located have been calculated as the average value. Eventually, there are 17 groups of data to conduct the fitting, which have been shown in Table 5 .

\section{Table 4}

The distance between villages and castles of the Ming Great Wall in Qinghai Province

\begin{tabular}{|c|c|c|c|}
\hline Number of Castles & $\begin{array}{l}\text { The distance between } \\
\text { castles and villages }(\mathrm{r}) / \mathrm{km}\end{array}$ & Number of Castles & $\begin{array}{c}\text { The distance between } \\
\text { castles and villages }(\mathrm{r}) / \mathrm{km}\end{array}$ \\
\hline 1 & 0.200 & 24 & 0.038 \\
\hline 2 & 0.500 & 25 & 0.226 \\
\hline 3 & 0.800 & 26 & 0.050 \\
\hline 4 & 1 & 27 & 0.000 \\
\hline 5 & 1 & 28 & 0.300 \\
\hline 6 & 0.126 & 29 & 0.000 \\
\hline 7 & 0.000 & 30 & 0.700 \\
\hline 8 & 1.710 & 31 & 0.000 \\
\hline 9 & 0.000 & 32 & 0.290 \\
\hline 10 & 0.300 & 33 & 0.000 \\
\hline 11 & 0.000 & 34 & 0.000 \\
\hline 12 & 0.000 & 35 & 0.000 \\
\hline 13 & 0.000 & 36 & 0.300 \\
\hline 14 & 0.130 & 37 & 0.280 \\
\hline 15 & 0.170 & 38 & 0.000 \\
\hline 16 & 0.200 & 39 & 0.000 \\
\hline 17 & 0.280 & 40 & 0.210 \\
\hline 18 & 0.000 & 41 & 0.000 \\
\hline 19 & 0.480 & 42 & 0.000 \\
\hline 20 & 0.000 & 43 & 0.000 \\
\hline 21 & 0.000 & 44 & 0.000 \\
\hline 22 & 0.000 & 45 & 0.000 \\
\hline 23 & 0.000 & 46 & 0.000 \\
\hline
\end{tabular}

Note: The No. 4 castle is far away from the village and there is no village close to the No. 5 castle, so the distances between such castles and villages were not considered in this research.

\section{Table 5}

The groups of fitting data in this research

\begin{tabular}{|c|c|c|c|}
\hline Number of groups & $\begin{array}{c}\text { Average villages population } \\
\text { density }\left(\mathrm{PD}_{0}\right) / \text { number per km }\end{array}$ & $\begin{array}{c}\text { Average distance between } \\
\text { castles and villages (r)/km }\end{array}$ & $\begin{array}{c}\text { Average Linear Loss Ratio } \\
(\mathrm{L}-\mathrm{VSR})\end{array}$ \\
\hline 1 & 6451 & 0.000 & $58.95 \%$ \\
\hline 2 & 3819 & 0.038 & $18.13 \%$ \\
\hline 3 & 4538 & 0.050 & $66.01 \%$ \\
\hline 4 & 2588 & 0.126 & $20.07 \%$ \\
\hline 5 & 12579 & 0.130 & $96.85 \%$ \\
\hline
\end{tabular}




\begin{tabular}{|c|c|c|c|}
\hline 6 & 12168 & 0.170 & $70.40 \%$ \\
\hline 7 & 8923 & 0.200 & $71.61 \%$ \\
\hline 8 & 3815 & 0.210 & $56.94 \%$ \\
\hline 9 & 17250 & 0.226 & $50.38 \%$ \\
\hline 10 & 6093 & 0.280 & $22.04 \%$ \\
\hline 11 & 4319 & 0.290 & $14.13 \%$ \\
\hline 12 & 3769 & 0.300 & $50.73 \%$ \\
\hline 13 & 7966 & 0.480 & $27.79 \%$ \\
\hline 14 & 6575 & 0.500 & $52.21 \%$ \\
\hline 15 & 12147 & 0.700 & $96.13 \%$ \\
\hline 16 & 8999 & 0.800 & $23.55 \%$ \\
\hline 17 & 19295 & 1.710 & $86.57 \%$ \\
\hline
\end{tabular}
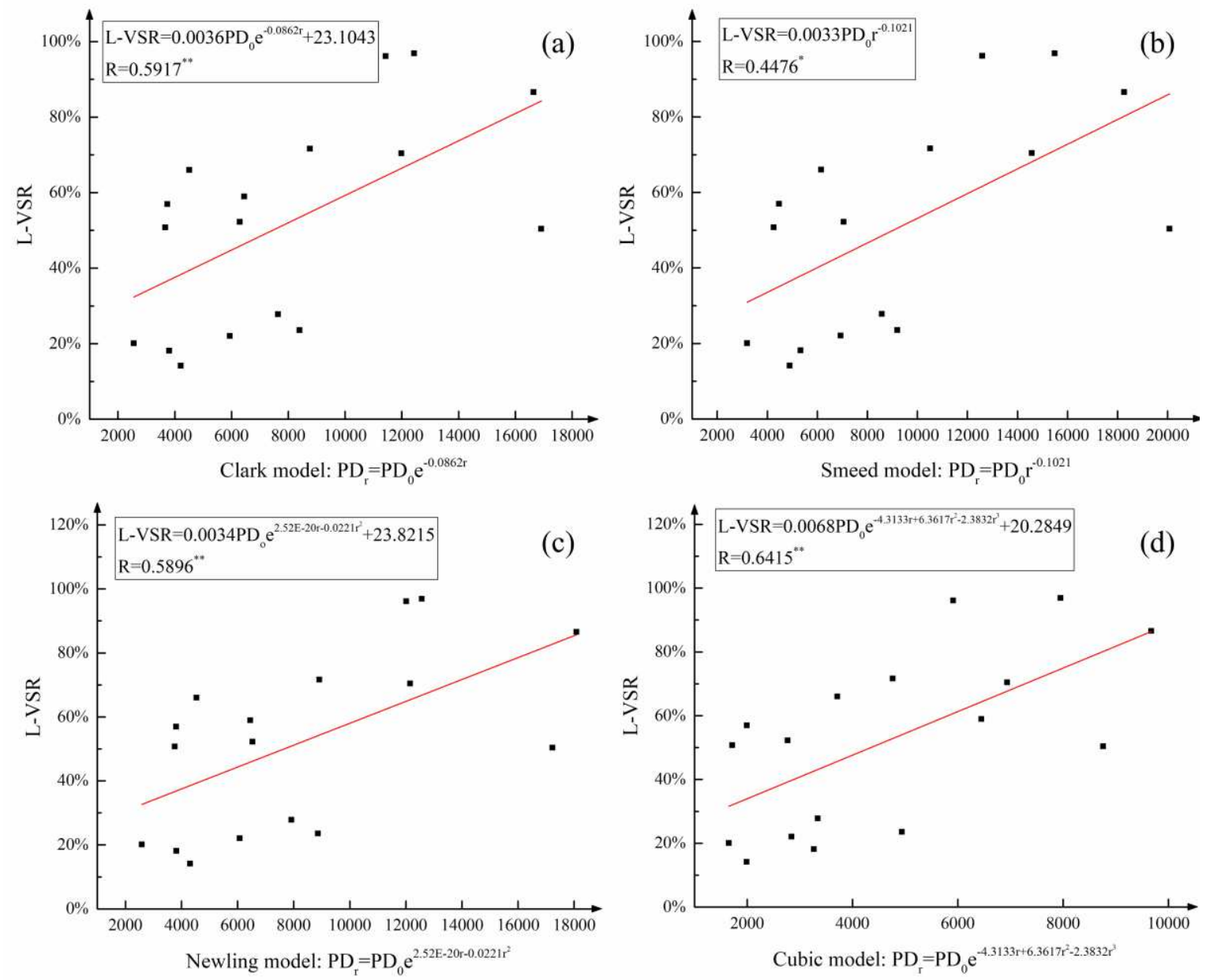

Fig. 5. The correlation graphs between $\mathrm{PD}_{\mathrm{r}}$ and L-VSR: a Clark model, b Smeed model, c Newling model, and d Cubic model. * and $* *$ represent the values of significance at $90 \%$ and $95 \%$ levels by the student's t-test, respectively.

To achieve optimal fitting effects, the optimization algorithm of Levenberg-Marquardt (LM) was used to determine the parameters in Eqs (4)-(7). After that, $\mathrm{PD}_{\mathrm{r}}$ can be calculated and the correlation between $\mathrm{PD}_{\mathrm{r}}$ and L-VSR can be further determined, as shown in Fig. 5. From the correlation results, the Cubic model has the largest correlation coefficient $(\mathrm{R}=0.6415)$, compared to the other three models. Therefore, the positive correlation between PD and L-VSR can be proved, and the anthropogenic influence on the conservation of earthen sites was revealed from a macroscopic perspective. 
In fact, human activities have very significant effects on the damage of earthen sites, and even artificial destruction in historical and contemporary processes has been regarded as one of the deterioration types of earthen sites [8,10,12]. For instance, local farmers directly dug soils from earthen sites (Fig. 6a), randomly added buildings along with earthen sites (Fig. 6b), and even dwelt behind earthen sites so that the earthen wall has to be used as their home enclosures (Fig. 6c and Fig. 6d). Some farming activities (Fig. 6e) and road engineering (Fig. 6f) also brought apparent influences on the earthen sites' conservation. However, to implement the Rules on the Great Wall Protection, the overall protective planning of the Ming Great Wall in Qinghai Province has been conducted orderly, which would effectively restrict human destruction under the joint efforts of government and individuals [28].

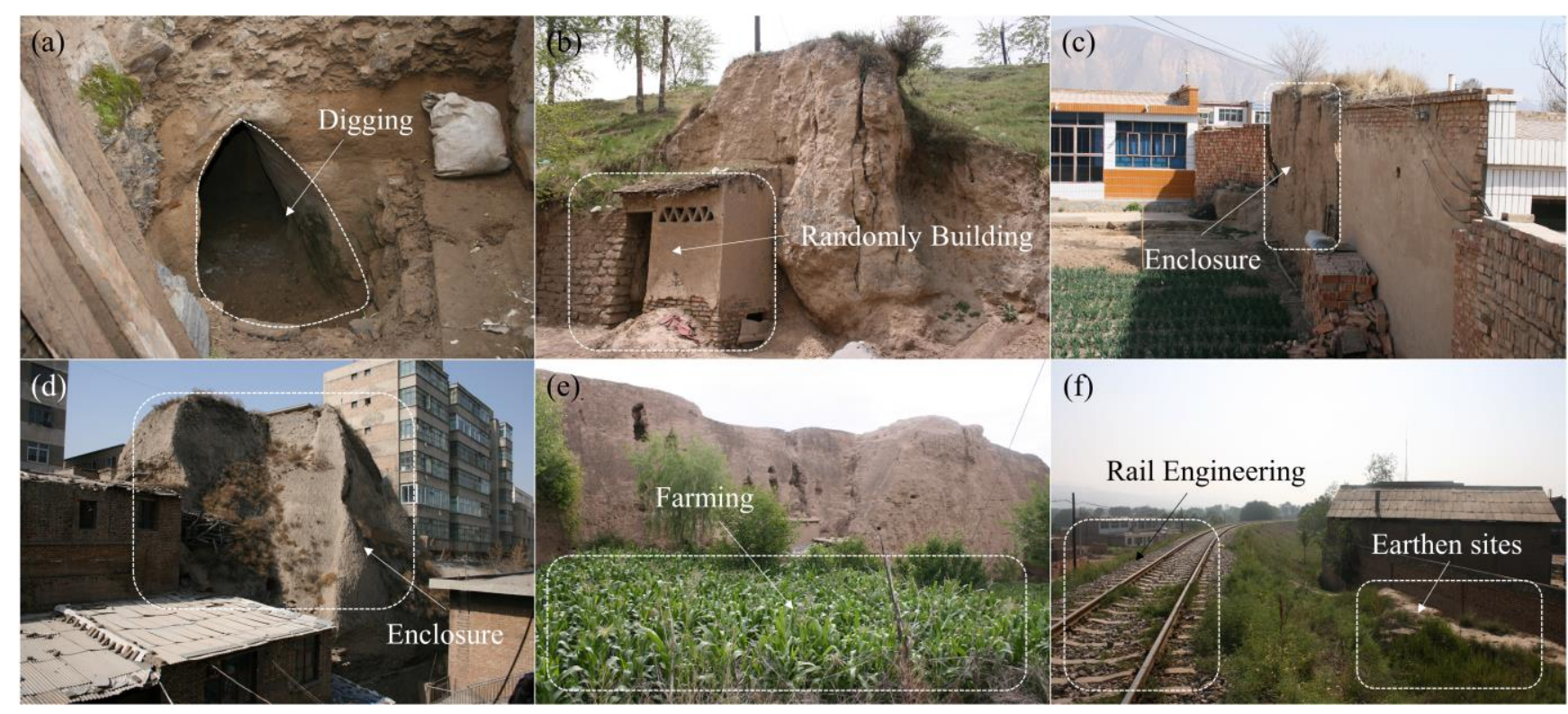

Fig. 6. The human activities graphs: a digging, $\mathbf{b}$ randomly building, $\mathbf{c}$ an enclosure in a peasant household, $\mathbf{d}$ an enclosure in an urban housing estate, $\mathbf{e}$ farming activities, and $\mathbf{f}$ rail engineering.

In this research, the aforementioned four population distribution models have a common assumption with the single core population distribution, meaning that the population density would generally decrease with the increment of distance from the residential center. Therefore, if the castle is much closer to the village, its conservation could be more obviously affected by more intense human activities, which has been proved from the fitting correlation results in Fig. 5. The flaw is that the correlation coefficient is not very large. The reason is that the population number has fluctuated with time. Especially, the Ming Great Wall has been built for about 500 years but the residential number in their locations each year is really hard to acquire. However, the population number in this research is only collected from the archaeological materials in 2008 provided by the Qinghai Bureau of Cultural Heritage. And the L-VSR data can also reflect the destruction status of castles in 2008 as the overall survey of castles was carried out in that year. This means that a good corresponding relationship between PD and L-VSR has been studied in this paper; Except for human influence, the damage of earthen sites is also closely related to the erosions of wind and rain and the vulnerability of rammed earth materials [9,13]. But a positive tendency between PD and L-VSR can be apparently seen from our research results, and correlation coefficients have passed the significant test, having statistical significance. Therefore, the indicator and model proposed in this research have scientificity and accuracy. In our future research, the models of L-VSR and PD will be further promoted and applied into other sections of the Ming Great Wall in NW China, to acquire more scientific and precise assessment outcomes of the conservation status of earthen sites by constantly revising and improving related parameters. What's more, the volume reflection data including the remaining height and the top and bottom width of earthen sites will be collected, and then the volume vanishing section ratio (V-VSR) can be further studied in the future. 


\section{Conclusion}

In this paper, 46 castles of the Ming Great Wall in Qinghai Province were chosen as research objects. The linear vanishing section ratio (L-VSR) was proposed to characterize such earthen sites' conservation status which can be divided into five levels including excellent $(\mathrm{E})(0-10 \%)$, good $(\mathrm{G})(10 \%-25 \%)$, fair $(\mathrm{F})(25 \%-50 \%)$, poor $(\mathrm{P})(50 \%-75 \%)$, and very poor $(\mathrm{VP})(75 \%$ $100 \%)$. By means of plane graphs of these castles, the remaining length (RL) and circumference length (CL) of castles were collected, and then L-VSR data were acquired.

Based on L-VSR values and corresponding classification ranges, there are 0 castles at the $\mathrm{E}$ status, 10 castles at the $\mathrm{G}$ status making up 22\% of the total castles, 9 castles at the F status accounting for 20\%, 10 castles (22\%) at the P status, and 16 castles (36\%) at the VP status, respectively. Hence, the castles at the excellent status constituted the minimum proportion, while the castles at the very poor status represented the largest percentage. There were more than half of the castles in the poor condition or even worse. These grading evaluation results have reflected the grave situation of earthen sites.

Moreover, the population density (PD) of villages in which castles are located or nearby was obtained. Combined with castles' conservation status results, the average PD data increased with the increment of overall damage level, meaning that the conservation status of earthen sites would worsen as the surrounding population grows.

By referring to four frequently-used single core population distribution models, namely the models of Clark, Smeed, Newling, and Cubic, a linear positive correlation between the population density of a position where the castle is located $\left(\mathrm{PD}_{\mathrm{r}}\right)$ and L-VSR was determined, and the Cubic model has the best fitting result.

According to our research findings, the novel indicator i.e., L-VSR is significant and applicable to characterize the conservation status of earthen sites, and the anthropogenic influence on the damage of earthen sites has been revealed from a macroscopic perspective. It is potential to promote the indicator and model proposed in this research into earthen sites and other architectural types of the Ming Great Wall, to acquire more scientific and precise assessment results of their conservation status by constantly revising and improving related parameters. Therefore, the research is beneficial to the overall conservation assessment of earthen sites, and also meaningful to their further preservation and protective planning.

\section{Abbreviations}

L-VSR: linear vanishing section ratio

PD: population density MDCM: multicriteria decision-making CL: circumference length RL: remaining length RLR: remaining length ratio E: excellent G: good $\mathbf{F}$ : fair P: poor VP: very poor RQD: rock quality designation PN: population number RA: region area V-VSR: volume vanishing section ratio

\section{Declarations}

\section{Authors' contributions}

Yumin Du and Wenwu Chen developed the methodology for this research. Kai Cui and Wenqiang Dong were responsible for collecting the population and sites data. Shuai Zhang and Qiyong Zhang were responsible for the model calculation. This manuscript was written by Yumin Du. Yumin Du also contributed to data analysis and processing. All authors read and approved the final manuscript.

\section{Authors details}

${ }^{1}$ Institute of Culture and Heritage, Northwestern Polytechnical University, Xi'an 710072, China;

${ }^{2}$ Key Scientific Research Base of the State Administration of Cultural Heritage for the Conservation and Restoration of Murals and Material Science Research, Northwestern Polytechnical University, Xi'an 710072, China;

${ }^{3}$ Key Laboratory of Mechanics on Disaster and Environment in Western China, College of Civil Engineering and Mechanics, Lanzhou University, Lanzhou 730000, China;

${ }^{4}$ Western Center for Disaster Mitigation in Civil Engineering of Ministry of Education of China, School of Civil Engineering, Lanzhou University of Technology, Lanzhou 730050, China 


\section{Acknowledgements}

This work was supported by the funding from National Key R\&D Plan Program of China (Grant No. 2020YFC1522201 and No. 2020YFC1521904), the cultural relics protection technology project of State Administration of Cultural Heritage of the People's Republic of China (Grant No. 2013-YB-SQ-120) and the National Natural Science Foundation of China (Grant No. 41562015 and No. 52068050).

\section{Competing interests}

The authors declare that they have no competing interests.

\section{Availability of data and materials}

The data that support the findings of this study are available from the corresponding author upon reasonable request.

\section{Funding}

This work was supported by the funding from National Key R\&D Plan Program of China (Grant No. 2020YFC1522201 and No. 2020YFC1521904), the cultural relics protection technology project of State Administration of Cultural Heritage of the People's Republic of China (Grant No. 2013-YB-SQ-120) and the National Natural Science Foundation of China (Grant No. 41562015 and No. 52068050).

\section{References:}

1. Fujii Y, Fodde E, Watanabe K, Murakami K. Digital photogrammetry for the documentation of structural damage in earthen archaeological sites: The case of Ajina Tepa, Tajikistan. Eng Geol. 2009;105:124-33.

2. Elert K, Sebastián E, Valverde I, Rodriguez-Navarro C. Alkaline treatment of clay minerals from the Alhambra Formation: Implications for the conservation of earthen architecture. Appl Clay Sci. 2008;39:122-32.

3. Matero F. Lessons from the Great House: Condition and treatment history as prologue to site conservation and management at Casa Grande Ruins National Monument. Conserv Manag Archaeol Sites. 1999;3:205-24.

4. Lercari N. Monitoring earthen archaeological heritage using multi-temporal terrestrial laser scanning and surface change detection. J Cult Herit. 2019;39:152-65.

5. Du Y, Chen W, Cui K, Gong S, Pu T, Fu X. A Model Characterizing deterioration at earthen sites of the Ming Great Wall in Qinghai Province, China. Soil Mech Found Eng. 2017;53:426-34.

6. Luo Y, Yang M, Ni P, Peng X, Yuan X. Degradation of rammed earth under wind-driven rain: The case of Fujian Tulou, China. Constr Build Mater. 2020;261:119989.

7. Pei QQ, Wang XD, Zhao LY, Zhang B, Guo QL. A sticky rice paste preparation method for reinforcing earthen heritage sites. J Cult Herit. 2020;44:98-109.

8. Wang X, Li Z, Chen W, Zhang H, Guo Q, Sun M, Wang S, Zhang B. Research on key technologies for the protection of earth sites. Beijing: Science Press; 2013.

9. Du Y, Chen W, Cui K, Zhang K. Study on damage assessment of earthen sites of the Ming Great Wall in Qinghai Province based on Fuzzy-AHP and AHP-TOPSIS. Int J Archit Herit. 2020;14:903-16.

10. Li L, Shao M, Wang S, Li Z. Preservation of earthen heritage sites on the Silk Road, northwest China from the impact of the environment. Environ Earth Sci. 2011;64:1625-39. 
11. Richards. J, Zhao G, Zhang H, Viles H. A controlled field experiment to investigate the deterioration of earthen heritage by wind and rain. Herit Sci. 2019;7:1-13.

12. Shao M, Li L, Wang S, Wang E, Li Z. Deterioration mechanisms of building materials of Jiaohe ruins in China. J Cult Herit. 2013;14:38-44.

13. Du Y, Chen W, Cui K, Zhang J, Chen Z, Zhang Q. Damage assessment of earthen sites of the Ming Great Wall in Qinghai Province: A comparison between Support Vector Machine (SVM) and BP Neural Network. J Comput Cult Herit. 2020;13:118.

14. Porter DW, Mehrotra A, DeJong MJ, Bass A, Guebard M, Ochsendorf J. Material and seismic assessment of the Great House at Casa Grande Ruins National Monument, Arizona. J Archit Eng. 2020;26:05019007.

15. Richards J, Viles H, Guo Q. The importance of wind as a driver of earthen heritage deterioration in dryland environments. Geomorphology. 2020;369:107363.

16. Su MM, Wall G. Community participation in tourism at a World Heritage Site: Mutianyu Great Wall, Beijing, China. Int J Tour Res. 2014;16:146-56.

17. Chen W, Du Y, Cui K, Fu X, Gong S. Architectural forms and distribution characteristics of beacon towers of the Ming Great Wall in Qinghai Province. J Asian Archit Build Eng. 2017;16:503-10.

18. Cao Y, Zhang Y. The fractal structure of the Ming Great Wall Military Defense System: A revised horizon over the relationship between the Great Wall and the military defense settlements. J Cult Herit. 2018;33:159-69.

19. Du Y, Chen W, Cui K, Guo Z, Wu G, Ren X. An exploration of the military defense system of the Ming Great Wall in Qinghai Province from the perspective of castle-based military settlements. Archaeol Anthropol Sci. 2021;13:46.

20. Ren X. Resources' investigation report of Ming Great Wall in Qinghai Province. Beijing: Cultural Relics Press; 2012.

21. Pu T, Chen W, Du Y, Li W, Su N. Snowfall-related deterioration behavior of the Ming Great Wall in the eastern QinghaiTibet Plateau. Nat Hazards. 2016;84:1539-50.

22. Deere DU, Deere DW (1988) The rock quality designation (RQD) index in practice. In: Kirkaldie L, editor. ASTM-STP 984. Philadelphia: American Society for Testing and Materials, 1988. p. 91-101

23. Smailes PJ, Argent N, Griffin TLC. Rural population density: its impact on social and demographic aspects of rural communities. J Rural Stud. 2002;18:385-404.

24. Clark C. Urban population densities. J R Stat Soc Ser A. 1951;114:490-6.

25. Smeed RJ. The effect of some kinds of routeing systems on the amount of traffic in the central areas of towns. J Inst Highw Eng. 1963; 10:5-26

26. Newling BE. The spatial variation of urban population densities. Geogr Rev. 1969;59:242-52.

27. Frankena MW. A bias in estimating urban population density functions. J Urban Econ. 1978;5:35-45.

28. Wu Z, Wei Y. The widespread consultation of the overall protective planning of the Ming Great Wall in Qinghai Province. 
Gt Wall. 2016;53-4. 


\section{Figures}

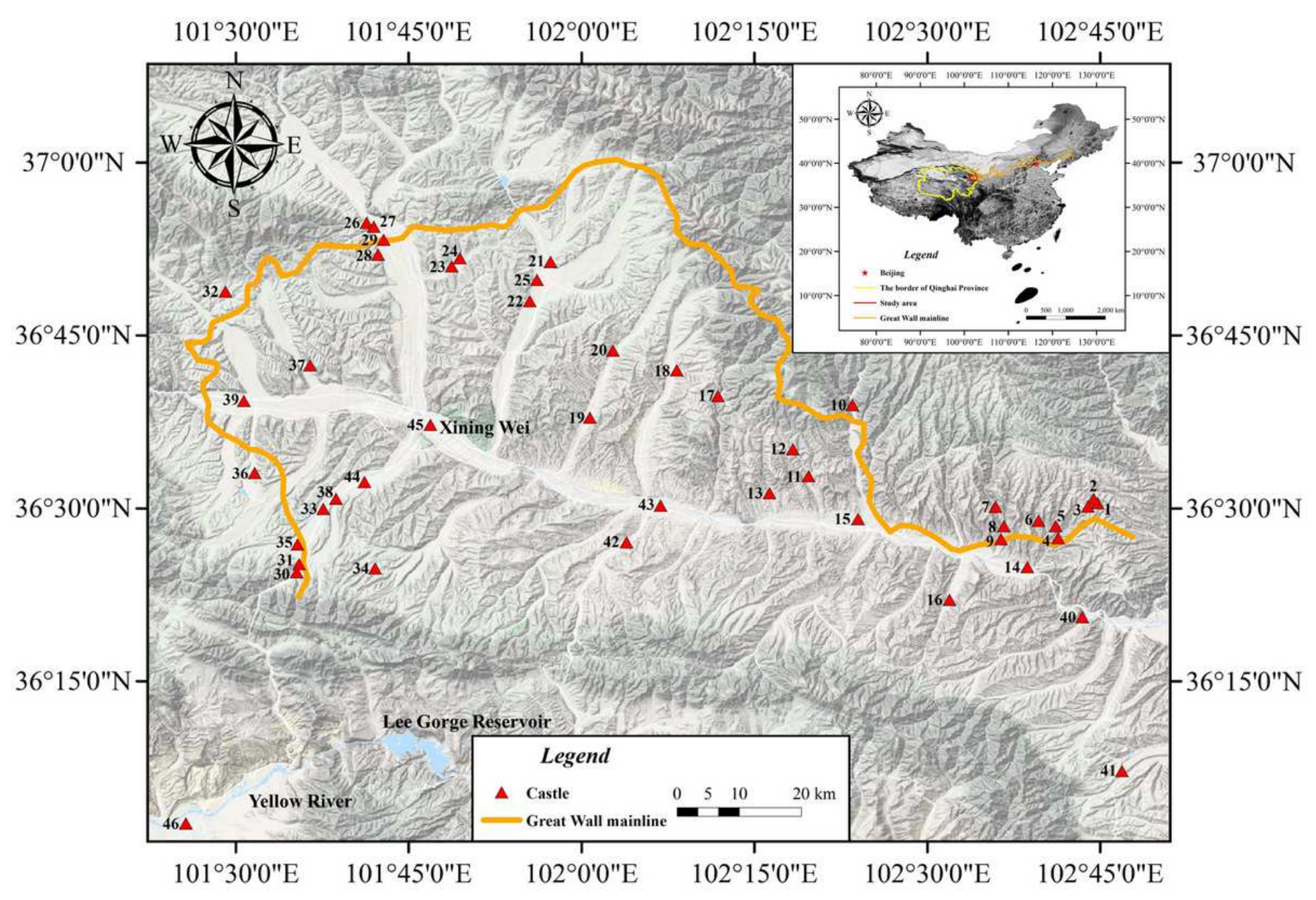

Figure 1

The distribution of castles of the Ming Great Wall in Qinghai Province. 


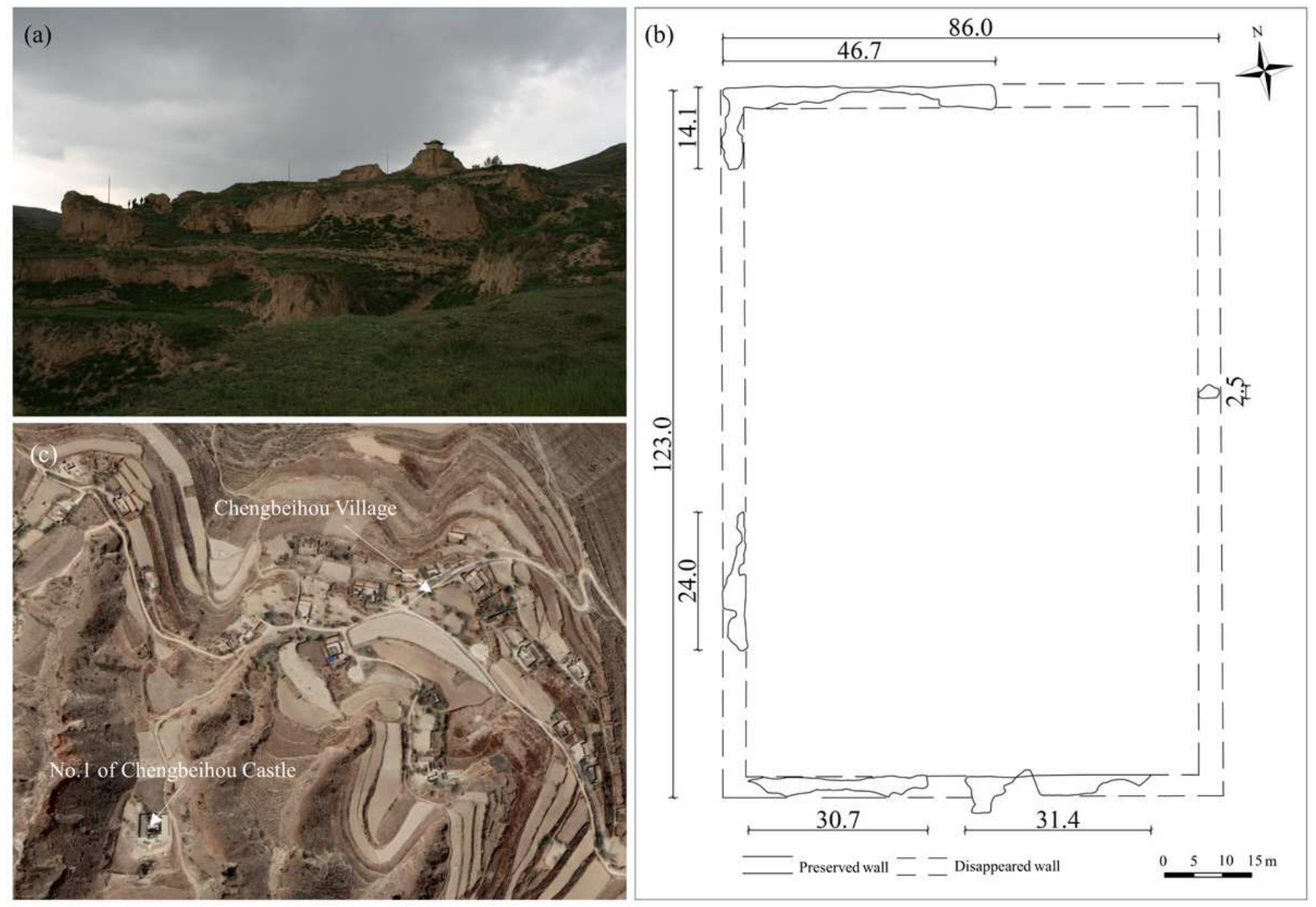

Figure 2

No.1 of Chengbeihou Castle: a front view, b plane graph, and c satellite image (from Google map). 


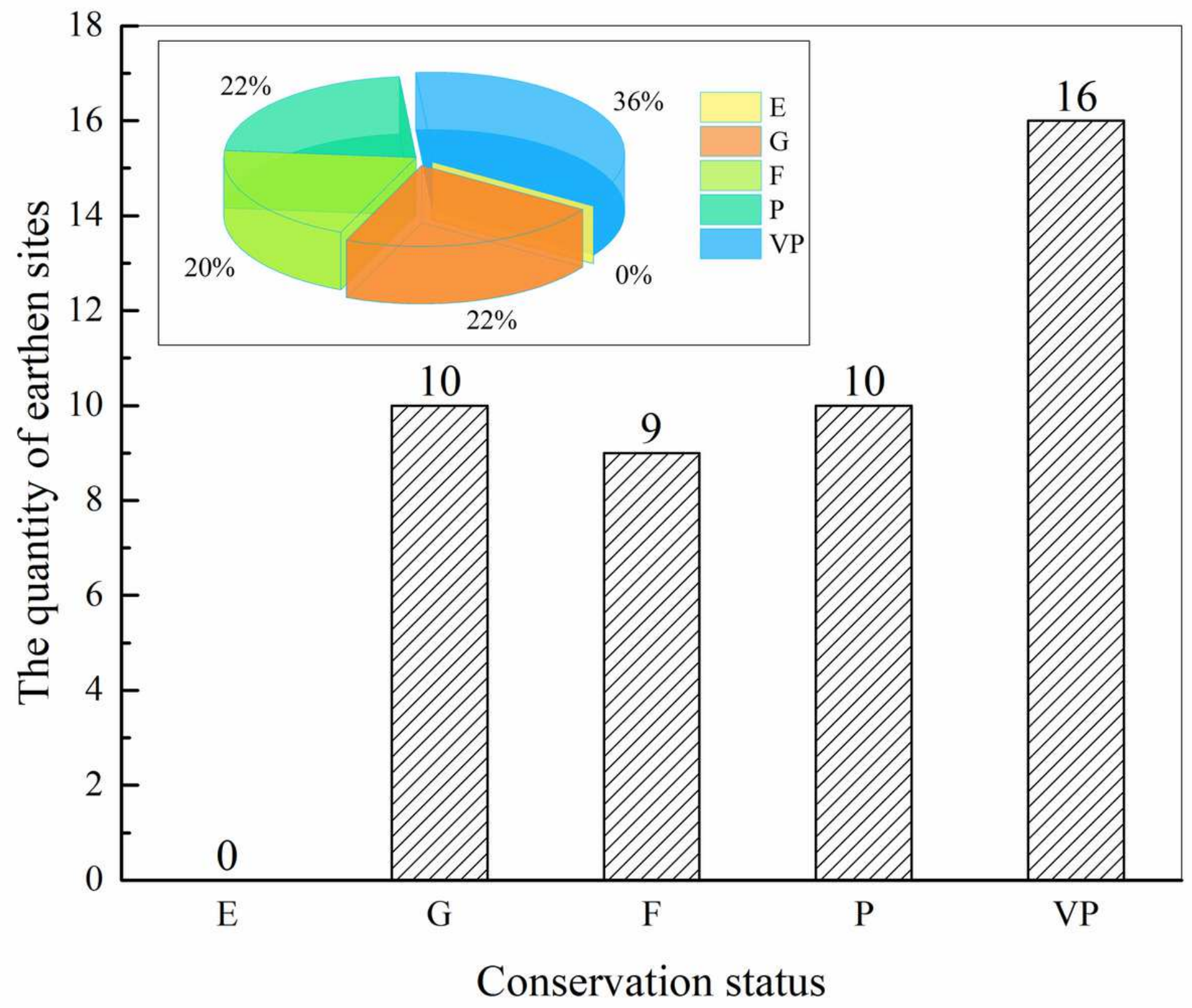

Figure 3

The conservation status of castles in Qinghai Province 


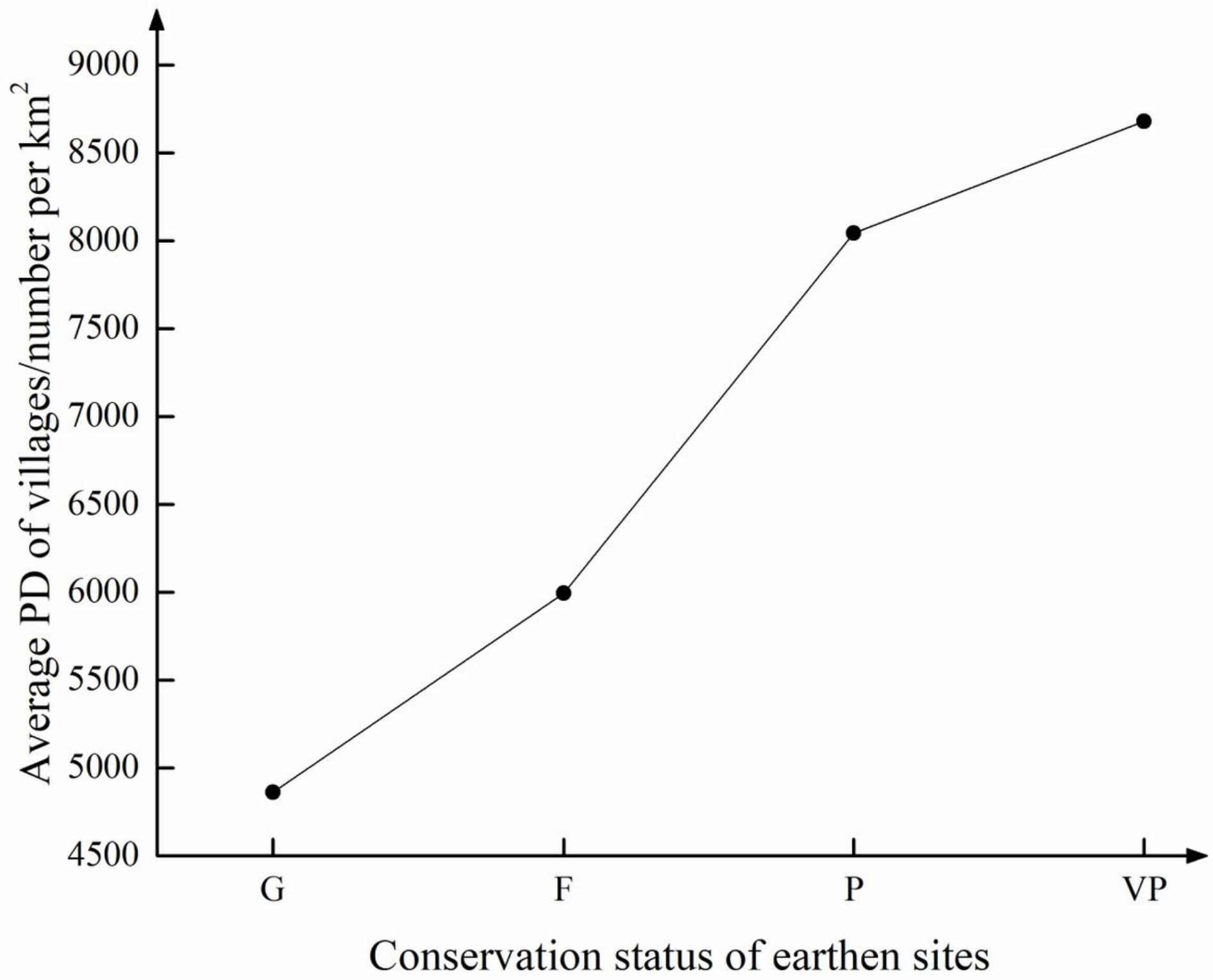

Figure 4

The tendency graph between PD and conservation status of castles in Qinghai Province 

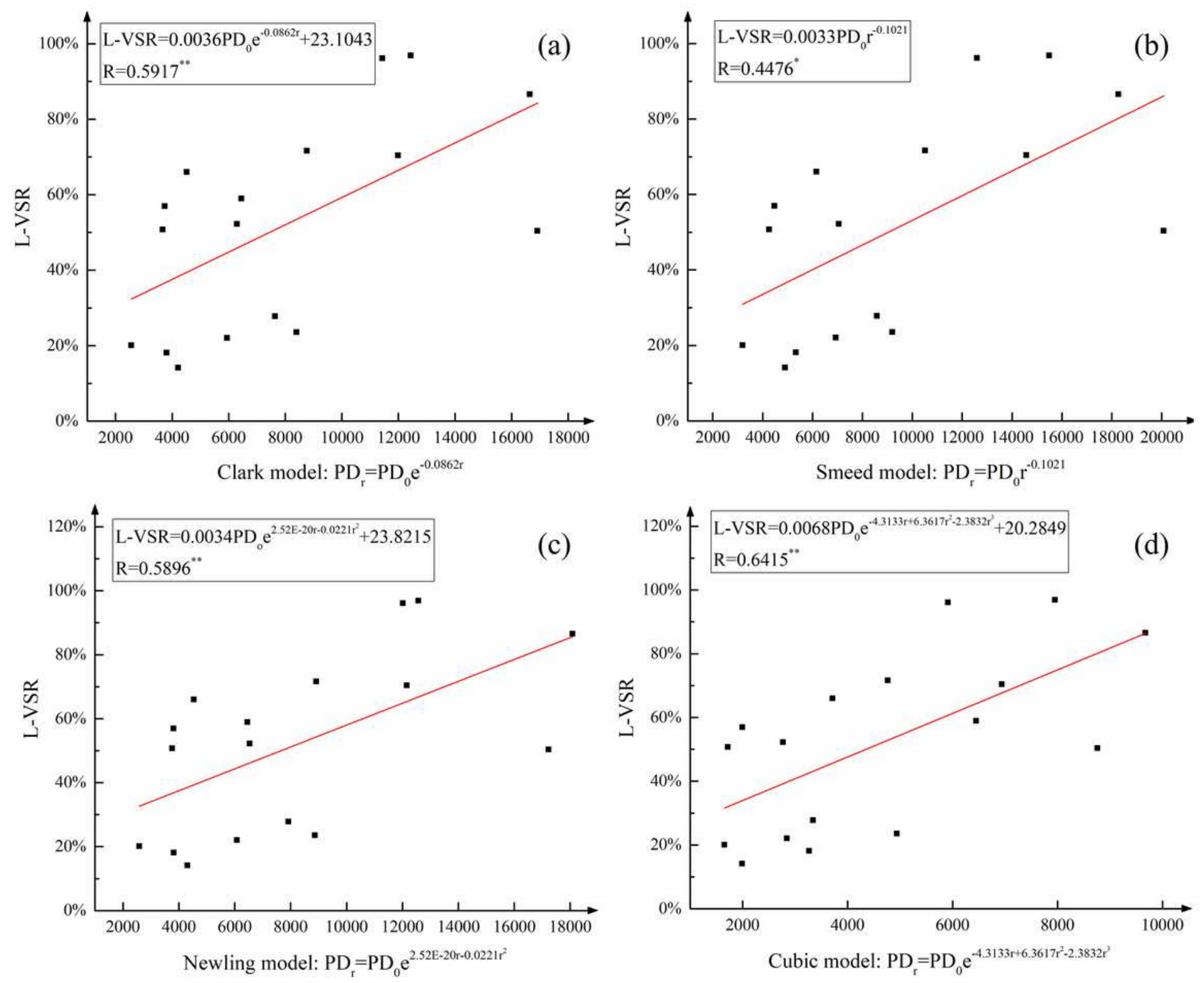

\section{Figure 5}

The correlation graphs between PDr and L-VSR: a Clark model, b Smeed model, c Newling model, and d Cubic model. * and ${ }^{* *}$ represent the values of significance at $90 \%$ and $95 \%$ levels by the student's t-test, respectively. 


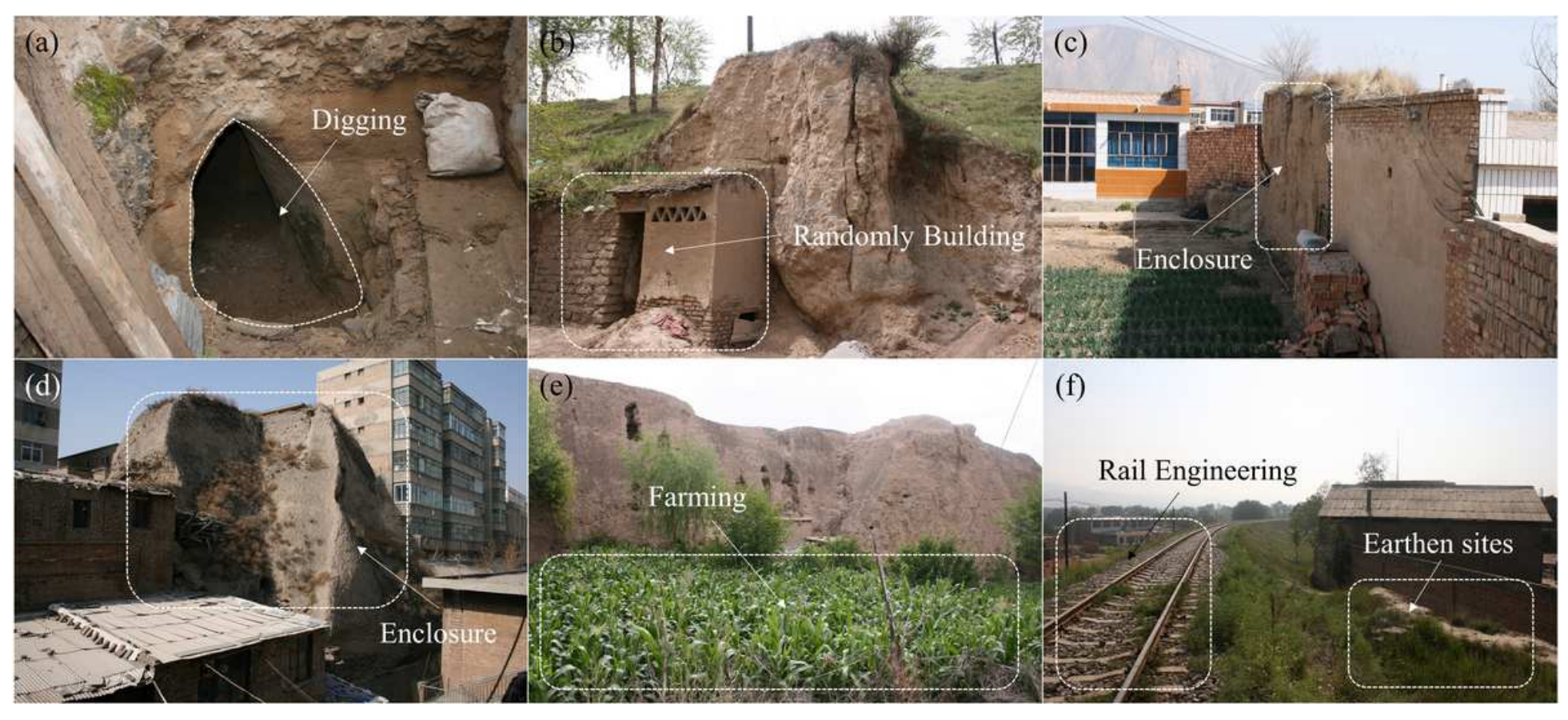

Figure 6

The human activities graphs: a digging, $b$ randomly building, $c$ an enclosure in a peasant household, $d$ an enclosure in an urban housing estate, e farming activities, and $f$ rail engineering. 